\title{
Lenguajes, estéticas y políticas actuales de los pueblos indígenas latinoamericanos.
}

En un momento en donde el mundo parece detenido a causa de la pandemia, los autores de este número se unen para explorar diferentes perspectivas de expresiones indígenas contemporáneas, mostrando la pertinencia de estudiar y analizar diferentes manifestaciones estéticas y lingüísticas de las comunidades latinoamericanas. En estos sietes ensayos se presentan análisis interdisciplinares que abordan la compleja definición del sujeto-político del indígena y su identidad particular a partir de procesos históricos que datan desde la conquista y la colonia. Eventos que se reconfiguran o tratan de restituirse y/o repararse a través de acciones del Estado en donde se incluye la visión multicultural del contexto latinoamericano actual, aunque en ese ejercicio político se repitan las brechas coloniales de normatividad entre la práctica y la ley. Tema que se presenta en el corpus analizado y, desde el cual, se relatan singularidades indígenas a través de estéticas del siglo XXI que consolidan una mirada autoafirmativa.

En el primer artículo encontramos un análisis de los textos de la escritora Wayuu Estercilia Simanca Pushaina y el arijuna-no wayuu Philip Potdevin. Su autor, Kevin Guerrieri, a través de las relaciones entre la literatura y el activismo, demuestra las evidencias históricas que se entrelazan con hechos políticos de reconocimiento estatal a la comunidad Wayuu, ubicada en el Norte de Colombia. El registro de ciudadanos con la asignación arbitraria de nombres y fechas de nacimiento a los miembros del colectivo, es un ejemplo de cómo los mecanismos "civilizadores" para ser reconocidos por parte del Estado se revirtió en contra de la identidad indígena del pueblo Wayúu, llevando a los escritores a crear desde la ficción elementos de conciencia crítica y política por medio de sus personajes.

El segundo artículo, "El contrabando de sueños y el tejido de sangre: una lectura ontológica de la poesía de Vito Apüshana", también se centra en la comunidad Wayúu y aborda la ontología del espíritu Joutai desde la poética de Apüshana. La autora, Adriana Campos, explora el concepto de "contrabando escritural" y le adjudica al poeta la función de "mediador cultural", ya que en los poemas se evidencia la interpelación a un colectivo que incluye al lector. En otros términos, la figura del espíritu del viento, descrita como ser mitológico en wayuunaiki, invita a los arijunas -no wayúu- al recorrido simbólico de peregrinaje que realizan por el desierto en busca de agua a causa de la sequía que afecta a la comunidad, debido a la explotación del Cerrejón. Esto nos indica que el territorio indígena se metaforiza como frontera entre el anfitrión y el visitante, una imagen ontológica que aborda la autora desde el recorrido que presenta el poeta por medio de Joutai.

En "Elvira Espejo Ayca y la oralidad del sujeto andino Aymara y Quechua" se presenta a la poeta, artista, tejedora e investigadora de la comunidad de Qaqachaka en Oruro, Bolivia. En este análisis, Adriana Sánchez retoma tres poemarios bilingües que presentan marcas de la oralidad en quechua y aymara, estableciendo tres rasgos de la poética: el primero, se relaciona con la recuperación de cantos sagrados de tiempos coloniales a través de las voces de sus abuelas en donde la reiteración de las palabras y los versos conservan las marcas lingüísticas de la lengua indígena; el segundo, la dinámica discursiva que explora entre la semántica impuesta en la época colonial y la experiencia con el mundo andino de la voz poética; y finalmente, el cuestionamiento de la memoria incaica que presentan los textos dando una interpretación crítica y de resistencia ante el proceso de la extirpación de la idolatría andina.

Con un interesante acercamiento a la literatura indígena contemporánea de Brasil, Leo Danner, Julie Dorrico y Fernando Danner reflexionan en torno a la escritura como fuerza de reconocimiento y resistencia política de los pueblos indígenas en su artículo "Autoria, autonomía, ativismo: educar e politizar pela e para a escrita - notas sobre a literatura indígena brasileira contemporánea". Los autores señalan que hay una lucha política que se mantiene para recuperar y entender el proceso de la identidad indígena desde el pasado, lo cual le permite a los sujetos-coloniales debatir y enfrentar la historia, ya no como minorías, sino como 
sujetos activos y políticos que reinterpretan la mirada eurocéntrica desde la práctica directa decolonial de la cultura, abriendo nuevas perspectivas a los procesos des-evangelizadores. Este activismo literario reivindica la autonomía y autoría de los pueblos indígenas reafirmando la singularidad y otredad de las perspectivas ontológicas, antropológicas y epistémicas.

Argelia González Hurtado, con su trabajo "Narrando la diáspora indígena a través de la cámara de Yolanda Cruz" introduce el análisis a la obra audiovisual de la cineasta mexico-estadounidense, Guenati'qá. The one who comes to visit (2004) y Sueños binacionales (2005), desde los cuales reflexiona acerca de la migración de los pueblos mixteco, chatino y zapoteco de Oaxaca hacia los Estados Unidos. De acuerdo a su interpretación, Cruz presenta las complejas relaciones de las identidades del indígena-migrante y propone el concepto de "identidades moldeadas", término que cuestiona la ontología del migrante desde la experiencia testimonial como herramienta de visibilidad política y pública en medio de una sociedad globalizada que elimina a los sujetos vulnerables.

El sexto artículo, "Metsá kené: los diseños y la identidad del pueblo shipibo-konibo" presenta el análisis del Kené como experiencia matrilineal de la cultura shipibo-konibo del Amazonas peruano. Sus autores Favaron y Bensho proponen la perspectiva indígena para interpretar la geometría de los diseños y nos recuerdan la memoria ancestral que se teje en el Kené y su relación con el territorio amazónico, en donde el agua de los pueblos complementa la vida. A través de la interpretación que hacen los autores, se entiende la expresión estética del kené como vínculo de afecto que conserva cada mujer con la particularidad de las experiencias de cada diseñadora con el territorio y sus antepasados. De esa manera, el kené es estética que trasciende la espiritualidad y ética de los shipibo-konibo, algo que alude a la relación ontológica de las expresiones artísticas de los pueblos indígenas latinoamericanos.

El dossier se cierra con el artículo "Money for nothing: la revolución no monetaria de los Andes", del poeta Odi Gonzáles. El autor presenta un análisis histórico-lingüístico de los los verbos ser y tener desde la perspectiva lingüística del quechua, según las concepciones del mundo andino. En el texto encontramos la mirada del quechua hablante y lingüista, en donde se contrapone la cosmogonía de la colectividad andina con el concepto de propiedad privada que impuso la Colonia. De igual manera, se comparan los conceptos de comprar y vender, ajenos a la concepción incaica del trueque, porque las transacciones comerciales de los Incas no implicaban el uso de posesivos y sufijos que en quechua pudieran denotar la misma semántica de los colonos; sin embargo, en ese proceso de adaptación del lenguaje, las estructuras morfológicas determinaron el uso de neologismos en quechua que adecuaban el sentido colectivo del 'ser' en los intercambios. 